\title{
Macrofauna do solo em uma cronosequência de capoeiras, florestas e pastos no Centro de Endemismo Belém, Amazônia Oriental
}

\author{
Guillaume Xavier ROUSSEAU ${ }^{*}$, Paulo Rogério dos Santos SILVA ${ }^{1}$, Danielle CELENTANO², \\ Claúdio José Reis de CARVALHO ${ }^{3}$ \\ 1 Universidade Estadual do Maranhão (UEMA). Programa de Pós-Graduação em Agroecologia. Cidade Universitária Paulo VI S/N, Tirirical, São Luis, Maranhão, Brasil, CEP 65055-970. \\ 2 Universidade Federal do Maranhão (UFMA). Rede de Biodiversidade e Biotecnologia da Amazônia Legal (Bionorte). Campus Universitário do Bacanga, Av. dos Portugueses s/n, \\ São Luis, Maranhão, Brasil, CEP 65000-000. \\ ${ }^{3}$ Embrapa Labex Europa. Agropolis International, 1000 Avenue Agropolis, F-34394 CEDEX 5, Montpellier, França. \\ * Autor correspondente: guilirous@yahoo.ca
}

\section{RESUMO}

O Centro de Endemismo Belém (CEB) -região biogeográfica localizada entre os rios Tocantins e Pindaré- é a área mais desmatada da Amazônia. Estudar a biota do solo dos remanescentes florestais e de áreas em regeneração (capoeiras) do CEB é fundamental para promover práticas agrícolas mais sustentáveis e orientar açóes de restauração de áreas degradadas. Dessa forma, o objetivo desse estudo foi identificar os principais determinantes da composição e da diversidade dos grandes táxons de macrofauna do solo (uso atual do solo, núcleos geográficos, histórico de uso, freqüência de fogo) em uma cronoseqüência de capoeiras e florestas no CEB. A macrofauna foi amostrada em oito áreas de capoeiras baixas (4-7 anos), seis áreas de capoeiras médias (11-15 anos), sete áreas de capoeiras altas (20-40 anos), oito áreas de remanescentes de florestas e três áreas de pastagem. Sua composição e diversidade foi estudada através de Análises de Componentes Principais e Entre-classes. Um total de 9.225 indivíduos pertencentes a 29 grandes taxóns (ordens ou famílias) foram coletados nas 32 parcelas amostradas. A composição da macrofauna se mostrou sensível ao efeito do histórico de uso do solo e identificou comunidades significativamente distintas entre as micro-regióes, havendo nessa escala efeito da cronosequência de capoeiras e florestas. A intensidade do uso do solo levou a redução da abundância e da riqueza de predadores, indicando alteraçóes significativas no funcionamento do solo. Esses resultados mostram um efeito duradouro da degradaçáo sobre a macrofauna do solo e conseqüentemente sobre suas funções ecológicas.

PALAVRAS-CHAVE: Bioindicador, Restauração, Manejo do solo, Invertebrados.

\section{Soil macrofauna in a chronosequence of fallows, old-growth forests and pastures in the Belém Endemism Center, Eastern Amazon}

\begin{abstract}
The Belém Endemism Center (CEB; the biogeographic region located between the Tocantins and Pindaré rivers) is the most deforested area of the Amazon. To study the soil biota of the remaining old-growth and second-growth forests is essential to promote more sustainable farming practices, and provide orientation for degraded land restoration. The aim of this study was to identify the main determinants of the composition and diversity of major taxa of soil macrofauna (current soil use, geographic centers, soil use history, fire frequency) in a chronosequence of fallows and forests in the CEB. Macrofauna was sampled in eight sites of young secondary forests (4-7 y), six sites of medium secondary forests (11-15 y), seven sites of "old" secondary forests $(20-40 \mathrm{y})$, eight sites of old-growth forest remnants and three sites of pastures. Its composition and diversity were analysed through Principal Component and Between-class Analyses. A total of 9.225 individuals from 29 major taxa (orders or families) were collected in the 32 plots. Soil macrofauna composition was very sensitive to soil use history and identified different communities among geographic centers. The intensity of soil use decreased the abundance and richness of predators, indicating long-lasting impacts of soil degradation on macrofauna composition and diversity, and therefore on soil ecological functions.
\end{abstract}

KEYWORDS: Bioindicator, Restoration, Soil management, Invertebrates. 


\section{INTRODUÇÃO}

$\mathrm{O}$ Centro de Endemismo Belém (CEB) é a região biogeográfica localizada entre os rios Tocantins e Pindaré. Essa regiấo foi a primeira fronteira de colonizaçáo da Amazônia brasileira e, atualmente, apenas um quarto de sua área está coberta por florestas sendo que a maioria dos remanescentes florestais se encontram fragmentados e fora de unidades de conservação (Silva et al. 2005; Almeida e Vieira 2010). Estudar esses fragmentos para resgatar informaçôes sobre sua biodiversidade e seus processos naturais é fundamental para entender o funcionamento desses sistemas e poder gerar ferramentas que garantam a sustentabilidade da agricultura que se estabeleceu sobre áreas semelhantes e a restauração de áreas degradadas. Nesse contexto, a integridade da biota do solo é imprescindível para manter a produtividade tanto dos ecossistemas naturais como dos agroecossistemas.

Os invertebrados do solo são os principais engenheiros da estrutura física do solo (Lavelle et al. 2006; Blouin et al. 2013) e são responsáveis por mediar serviços ecossistêmicos essenciais como a produção de solo, a ciclagem dos nutrientes e a produção vegetal (MEA 2005). Embora os sistemas agrícolas tenham uma biota do solo diferente em abundância e composiçấo do que os ecossistemas naturais dos quais eles derivam, sabe-se que as funçôes ecológicas da biota original devem ser conservadas para garantir sua sustentabilidade (Chauvel et al. 1999; Lavelle et al. 2006), especialmente em solos com grande fragilidade estrutural como no CEB (Moura et al. 2009).

Dessa forma, é preciso conhecer a biodiversidade do solo tanto dos ecossistemas originais como as mudanças das comunidades que acompanham a conversão do uso do solo e a restauração natural dos solos degradados pelo uso intensivo. Uma abordagem para entender o papel dos invertebrados no funcionamento do solo é identificar os grupos-chave e determinar quais são os fatores que mais afetam sua composição nos diferentes usos do solo. Os fatores mais estudados são a intensidade do uso do solo (Mathieu et al. 2005), a duraçáo do pousio (abandono) (Rossi et al. 2010), o fogo (Gongalsky et al. 2012) e a restauração ativa (Pais e Varanda 2010). De modo geral, a maior intensidade de uso, a reduçáo do pousio e o aumento da freqüência do fogo levam a uma redução da diversidade e abundância da maioria dos grupos da macrofauna. No entanto, os resultados disponíveis permanecem escassos e pontuais, o que náo permite a formulaçáo de modelos teóricos consolidados para explicar os efeitos das mudanças do uso do solo. A imensa variabilidade dos solos requer dados locais para adaptar os modelos teóricos a cada tipo de solo (Wardle 2006). Dessa forma, o objetivo desse estudo foi identificar os principais determinantes da composição e da diversidade dos grandes táxons de macrofauna do solo (uso atual do solo, micro-regiôes, histórico de uso, freqüência de fogo) em uma cronoseqüência de capoeiras e florestas no Centro de Endemismo Belém.

\section{MATERIAL E MÉTODOS}

Desenho experimental e áreas de estudo - Foram amostradas oito áreas de capoeiras baixas (CB) entre 4-7 anos, seis áreas de capoeiras médias (CM) entre 11-15 anos, sete áreas de capoeiras altas (CA) entre 20-40 anos, oito áreas de remanescentes de floresta primária $(\mathrm{F})$ e três áreas de pastagem (P) na Amazônia Oriental. Cada área de estudo foi georeferenciada e foram instaladas parcelas circulares de 50 $\mathrm{m}$ de diâmetro divididas em quatro sub-parcelas. As parcelas estudadas foram agrupadas em "núcleos" ou micro-regiōes dentro do Centro de Endemismo Belém (Tabela 1, Figura 1). O núcleo $1(\mathrm{Gu})$ com 10 parcelas está na Reserva Biológica (Rebio) do Gurupi e assentamentos vizinhos em Itinga do Maranháo, sendo que dentro da Rebio as parcelas avaliadas fazem parte do Programa de Pesquisa em Biodiversidade (PPBio/MCT). O núcleo 2 (SL) com 4 parcelas está em São Luís/MA na Fazenda Escola da Universidade Estadual do Maranhão (UEMA). O núcleo 3 (Li) com 7 parcelas está na Ilha do Livramento no município de Alcântara/ MA. O núcleo 4 (TA) com 6 parcelas está localizado em Tomé-Açu/ PA em fazendas de produtores associados a Cooperativa Agrícola Mista de Tomé-Açu (CAMTA). O núcleo 5 (IA) com 5 parcelas está em Igarapé-Açu/PA nas parcelas do Projeto Tipitamba (Embrapa) localizadas na Fazenda Escola da Universidade Federal Rural da Amazônia (UFRA) e na comunidade de Santa Luzia. Todas as áreas, exceto São Luís, estão na regiấo biogeográfica denominada Centro de Endemismo Belém (CEB) com clima tropical chuvoso (zona climática A) e duas formações sedimentares Barreira e Itapecuru. O solo predominante na região é o Latossolo amarelo (Almeida e Vieira 2010).

Amostragem da macrofauna - A macrofauna foi amostrada de acordo com o método Tropical Soil Biology and Fertility/ TSBF (Anderson e Ingram 1993) modificado. Ao menos cinco monólitos de solo de $25 \times 25 \times 10 \mathrm{~cm}$ foram amostrados por parcela, no centro e a $20 \mathrm{~m}$ nas 4 direçôes (em cruz). As parcelas de Igarapé-Açu tiveram um esforço amostral maior (21 monólitos) por ser parte de um experimento dedicado a construçáo de um índice de qualidade do solo (ver Rousseau et al. 2010 para detalhes). Para cada monólito, a serapilheira e o solo foram amostrados separadamente e todos os invertebrados visíveis a olho nu imediatamente extraídos manualmente (1 pessoa/ monólito/ dia) e conservados em álcool 70\%. Depois de $24 \mathrm{~h}$ no máximo, as minhocas foram transferidas para o formol $4 \%$ onde permaneceram 1 mês antes da substituição do formol pelo álcool 70\%. A macrofauna foi contada e classificada em nível de grandes grupos taxonômicos (ordens 


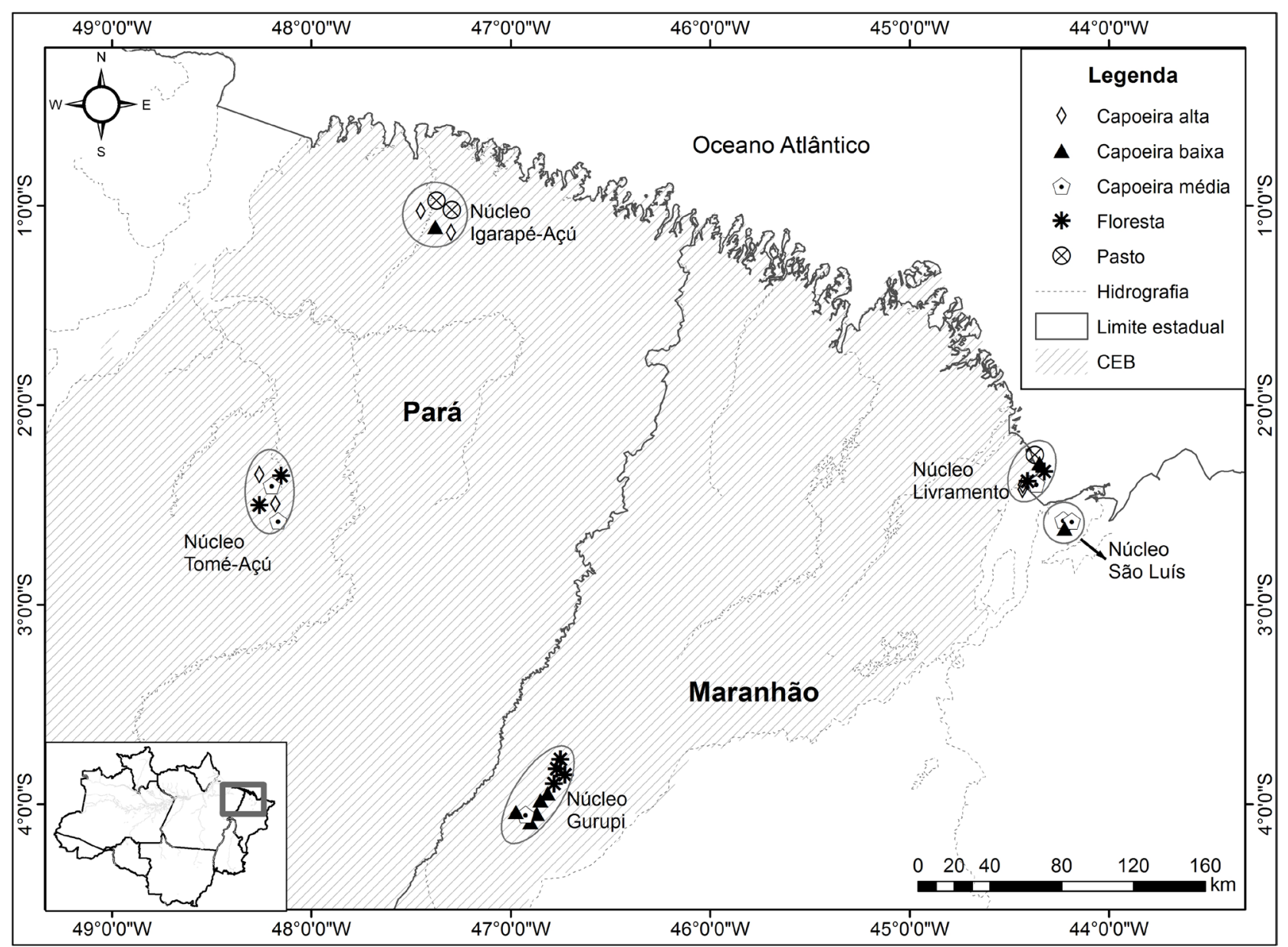

Figura 1. Mapa dos núcleos estudados (Gurupi/MA, Livramento/MA, São Luis/MA, Igarapé-Açú/PA e Tomé-Açú/PA) com a localização das parcelas segundo os diferentes usos do solo (pasto, capoeiras altas, médias e baixas e floresta) no Centro de Endemismo Belém, Amazônia Oriental

ou famílias) (Lavelle et al. 2003) e de acordo com suas funçôes ecológicas (Moço et al. 2010) (Tabela 2).

Análises estatísticas - Para cada núcleo estudado, foram realizadas curvas de acumulaçáo dos táxons da macrofauna (Figura 1A, apêndice) para cada uso do solo com o uso do software Estimates 9.1.0 (Colwell 2013). A média dos cinco monólitos foi utilizada para caracterizar as parcelas (Rossi et al. 2006). A variabilidade entre as parcelas foi alta (409-5.232 indivíduos $\mathrm{m}^{-2}$, desvio padrão=1088) e por isso a comunidade da macrofauna foi estudada através de Análise de Componentes Principais (ACP) e ACP entreclasses (ACP-C), e os efeitos dos fatores do estudo foram considerados significativos quando $\mathrm{P}<0,05$. Dessa forma, as análises sobre a abundância e diversidade (riqueza, diversidade de Shannon-Wiener, Simpson e equitatividade de Pielou) da macrofauna do solo foram realizadas em três etapas: 1) ACP para estudar as correlaçôes entre os táxons encontrados e ter uma visão geral da distribuição das parcelas em função da abundância dos grupos; 2) ACP-C para medir e testar por permutaçôes (Monte Carlo) o efeito dos fatores do estudo (uso atual do solo, núcleos, histórico de uso, freqüência de fogo) sobre a composição e diversidade da macrofauna (Chessel et al. 2004) (Tabela 1); 3) teste por permutaçóes do efeito dos fatores sobre cada grupo de macrofauna individualmente (Tabela 2). A idade, o histórico de uso e a freqüência de fogo foram estimados a partir de entrevistas com os proprietários ou os gestores no caso da Rebio do Gurupi (Tabela 1). Para minimizar as incertezas sobre a idade das capoeiras, elas foram organizadas em classes de idade como descrito anteriormente. A freqüência de fogo foi estimada de acordo com uma escala de 0 a 3: 0 - sem registro ou evidência de fogo; 1 - freqüência baixa (fogo ocasional); 2- freqüência média (queima regular para agricultura); 3-freqüência alta (queima anual durante o período de uso) (Tabela 1). As análises foram realizadas com o pacote ade4 (Chessel et al. 2004) do software livre R (R Development Core Team 2009). 
Tabela 1. Lista das 32 parcelas de capoeiras, florestas e pastos e determinantes da composição da macrofauna do solo estudados. Análise (ACP entre-classes) dos fatores do estudo sobre a composição e diversidade da macrofauna.

\begin{tabular}{|c|c|c|c|c|c|c|c|c|}
\hline \multirow{2}{*}{$\frac{\text { Parcela }}{1}$} & \multirow{2}{*}{$\begin{array}{l}\text { Uso atual } \\
\text { Floresta }\end{array}$} & \multirow{2}{*}{$\begin{array}{l}\text { Tipo vegetação } \\
\text { Amazônica }\end{array}$} & \multirow{2}{*}{$\begin{array}{l}\text { Núcleos } \\
\text { Gurupi }\end{array}$} & \multicolumn{2}{|c|}{$\begin{array}{l}\text { Coordenada Geográfica } \\
\text { (S/ W) }\end{array}$} & \multirow{2}{*}{$\begin{array}{l}\text { Histórico de uso } \\
\text { Exploração seletiva }\end{array}$} & \multirow{2}{*}{$\begin{array}{l}\text { Freqüência } \\
\text { de fogo }{ }^{\dagger} \\
0\end{array}$} & \multirow{2}{*}{$\begin{array}{l}\text { Sigla/idade } \\
\text { FAE100a }\end{array}$} \\
\hline & & & & 0392'19"' & $46^{\circ} 76^{\prime} 23^{\prime \prime}$ & & & \\
\hline 2 & Capoeira Baixa & Amazônica & Gurupi & $04^{\circ} 00^{\prime} 14^{\prime \prime}$ & $46^{\circ} 83^{\prime} 56^{\prime \prime}$ & Exploração seletiva & 1 & FAE6 \\
\hline 3 & Floresta alta & Restinga & Livramento & $02^{\circ} 25^{\prime} 03^{\prime \prime}$ & $44^{\circ} 25^{\prime} 20^{\prime \prime}$ & Exploração seletiva & 0 & FRE100a \\
\hline 4 & Capoeira baixa & Restinga & Livramento & $02^{\circ} 25^{\prime} 25^{\prime \prime}$ & $44^{\circ} 25^{\prime} 32^{\prime \prime}$ & Extrativismo & 2 & CR6 \\
\hline 5 & Capoeira média & Restinga & Livramento & $02^{\circ} 25^{\prime} 33^{\prime \prime}$ & $44^{\circ} 25^{\prime} 21^{\prime \prime}$ & Extrativismo & 2 & CR15 \\
\hline 6 & Pasto extensivo & Campo & Livramento & $02^{\circ} 25^{\prime} 26^{\prime \prime}$ & $44^{\circ} 25^{\prime} 31^{\prime \prime}$ & Pasto & 3 & P6a \\
\hline 7 & Capoeira média & Amazônica & São Luís & $02^{\circ} 58^{\prime} 74^{\prime \prime}$ & 4421'19'" & Corte-queima & 2 & CQ15a \\
\hline 8 & Capoeira alta & Amazônica & São Luís & $02^{\circ} 58^{\prime} 73^{\prime \prime}$ & $44^{\circ} 20^{\prime} 88^{\prime \prime}$ & Corte-queima & 2 & CQ25 \\
\hline 9 & Capoeira média & Amazônica & São Luís & $02^{\circ} 59^{\prime} 20^{\prime \prime}$ & 4420'92'” & Corte-queima & 2 & CQ15b \\
\hline 10 & Capoeira baixa & Amazônica & São Luís & $02^{\circ} 59^{\prime} 18^{\prime \prime}$ & 4421'04'" & Corte-queima & 2 & CQ5 \\
\hline 11 & Capoeira baixa & Amazônica & Gurupi & $04^{\circ} 07^{\prime} 11^{\prime \prime}$ & $46^{\circ} 90^{\prime} 76^{\prime \prime}$ & Exploração intensiva & 1 & FAD3a \\
\hline 12 & Capoeira baixa & Amazônica & Gurupi & $04^{\circ} 06^{\prime} 44^{\prime \prime}$ & $46^{\circ} 89^{\prime} 99^{\prime \prime}$ & Exploração intensiva & 1 & FAD3b \\
\hline 13 & Capoeira baixa & Amazônica & Gurupi & $04^{\circ} 05^{\prime} 22^{\prime \prime}$ & $46^{\circ} 93^{\prime} 27^{\prime \prime}$ & Exploração intensiva & 1 & FAD7 \\
\hline 14 & Capoeira média & Amazônica & Gurupi & $04^{\circ} 05^{\prime} 58^{\prime \prime}$ & 46092'76"' & Exploração intensiva & 1 & FAD11 \\
\hline 15 & Capoeira baixa & Amazônica & Gurupi & 03॰99'99"' & $46^{\circ} 83^{\prime} 64^{\prime \prime}$ & Exploração seletiva & 1 & FAE7 \\
\hline 16 & Floresta & Amazônica & Gurupi & $03^{\circ} 89^{\prime} 05^{\prime \prime}$ & $46^{\circ} 77^{\prime} 08^{\prime \prime}$ & Exploração seletiva & 0 & FAE100b \\
\hline 17 & Floresta & Amazônica & Gurupi & $03^{\circ} 89^{\prime} 08^{\prime \prime}$ & $46^{\circ} 77^{\prime} 10^{\prime \prime}$ & Exploração seletiva & 0 & FAE100c \\
\hline 18 & Floresta & Amazônica & Gurupi & 03⒐'78'" & $46^{\circ} 83^{\prime} 58^{\prime \prime}$ & Exploração seletiva & 0 & FAE100d \\
\hline 19 & Floresta alta & Restinga & Livramento & $02^{\circ} 41^{\prime} 61^{\prime \prime}$ & $44^{\circ} 42^{\prime} 53^{\prime \prime}$ & Exploração seletiva & 0 & FRE100b \\
\hline 20 & Capoeira alta & Restinga & Livramento & $02^{\circ} 41^{\prime} 65^{\prime \prime}$ & $44^{\circ} 42^{\prime} 45^{\prime \prime}$ & Extrativismo & 2 & CR30a \\
\hline 21 & Capoeira alta & Restinga & Livramento & $02^{\circ} 41^{\prime} 67^{\prime \prime}$ & $44^{\circ} 42^{\prime} 46^{\prime \prime}$ & Extrativismo & 2 & CR30b \\
\hline 22 & Floresta & Amazônica & Tomé-Açu & $02^{\circ} 39^{\prime} 42^{\prime \prime}$ & $48^{\circ} 16^{\prime} 43^{\prime \prime}$ & Sem intervenção & 0 & FA100 \\
\hline 23 & Floresta & Amazônica & Tomé-Açu & $02^{\circ} 50^{\prime} 16^{\prime \prime}$ & $48^{\circ} 29^{\prime} 06^{\prime \prime}$ & Exploração seletiva & 0 & FAE100e \\
\hline 24 & Capoeira alta & Amazônica & Tomé-Açu & $02^{\circ} 41^{\prime} 27^{\prime \prime}$ & 48019'76"' & Pasto & 2 & P26 \\
\hline 25 & Capoeira alta & Amazônica & Tomé-Açu & $02^{\circ} 34^{\prime} 84^{\prime \prime}$ & $48^{\circ} 25^{\prime} 98^{\prime \prime}$ & Corte-queima & 2 & CQ23 \\
\hline 26 & Capoeira média & Amazônica & Tomé-Açu & $02^{\circ} 40^{\prime} 18^{\prime \prime}$ & 48019'68"' & Pasto & 2 & $\mathrm{P} 12 \mathrm{a}$ \\
\hline 27 & Capoeira média & Amazônica & Tomé-Açu & $02^{\circ} 41^{\prime} 27^{\prime \prime}$ & $48^{\circ} 19^{\prime} 76^{\prime \prime}$ & Pasto & 2 & $\mathrm{P} 12 \mathrm{~b}$ \\
\hline 28 & Capoeira baixa & Amazônica & Igarapé-Açu & $01^{\circ} 01^{\prime} 38^{\prime \prime}$ & 47038'06"' & Corte-queima & 2 & CQ4 \\
\hline 29 & Capoeira alta & Amazônica & Igarapé-Açu & $01^{\circ} 00^{\prime} 36^{\prime \prime}$ & 47038'35'” & Corte-queima & 2 & CQ20 \\
\hline 30 & Capoeira alta & Amazônica & Igarapé-Açu & 01011'24"' & 4731'59"' & Hevea brasiliensis & 1 & HB40 \\
\hline 31 & Pasto intensivo & Amazônica & Igarapé-Açu & $01^{\circ} 02^{\prime} 34^{\prime \prime}$ & $47^{\circ} 29^{\prime} 40^{\prime \prime}$ & Corte-queima & 2 & P6b \\
\hline 32 & Pasto intensivo & Amazônica & Igarapé-Açu & $01^{\circ} 00^{\prime} 03^{\prime \prime}$ & 47037'53"' & Corte-queima & 2 & P6c \\
\hline $\mathrm{R}(\%)$ & 14,9 & - & 25,2 & - & & $31,7 \%$ & 12,1 & - \\
\hline$P \S$ & 0,16 & - & 0,0001 & - & & 0,0005 & 0,12 & - \\
\hline
\end{tabular}

† Freqüência de fogo: 0- sem registro ou evidência de fogo; 1- freqüência baixa (fogo ocasional); 2- freqüência média (queima regular para agricultura);

3- freqüência alta (queima anual durante o período de uso)

$\S \mathrm{p}<0,05$ indica variável com influência significativa segundo teste de Monte Carlo (9999 permutações aleatórias).

\section{RESULTADOS}

Um total de 9.225 indivíduos foram coletados nas 32 parcelas amostradas. Desse total, 29 grupos de macroinvertebrados foram identificados, sendo os grupos dominantes: Isoptera (41\%), Formicidae (30\%) e Oligochaeta (14\%). Coleoptera (3,5\%), Chilopoda (2,1\%), Diplopoda (1,8\%) e Aranae $(1,7 \%)$ apresentaram abundância intermediária enquanto todos os outros grupos apresentam abundância baixa $(<1 \%)$. As médias para cada grupo e as estatísticas básicas da comunidade (densidade, riqueza, diversidade de
Shannon-Wiener, Simpson e equitabilidade de Pielou) estáo apresentadas na Tabela 2. As curvas do coletor apresentadas na Figura 1A (apêndice), mostram uma estabilização no acúmulo de táxons somente para os pastos (> 40 monólitos) e capoeira média (> 20 monólitos) de Igarapé-Açu assim como as capoeiras médias do Livramento (> 8 monólitos). No entanto, o acúmulo de táxons novos é muito lento depois do quinto monólito na maioria dos usos e núcleos.

Análise de componentes principais - Os quatro primeiros componentes principais (CP) explicaram $47,8 \%$ da variância 
ACTA

AMAZONICA
Macrofauna do solo em uma cronoseqüência de capoeiras, florestas

e pastos no Centro de Endemismo Belém, Amazônia Oriental

\begin{tabular}{|c|c|c|c|c|c|c|c|}
\hline & $\tilde{\simeq}$ & 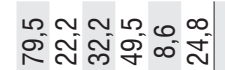 & 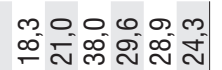 & 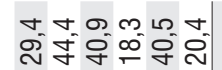 & 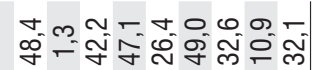 & 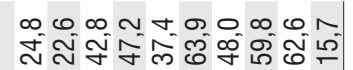 & \\
\hline & e & 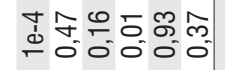 & 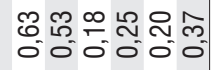 & 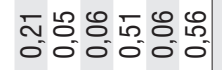 & 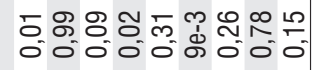 & 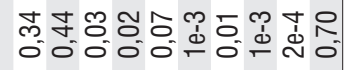 & \\
\hline & 氒 & to & 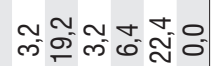 & जूञ & 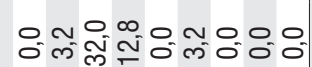 & 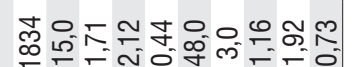 & \\
\hline & 崫 & 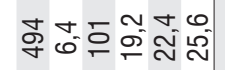 & 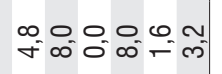 & 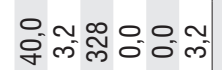 & 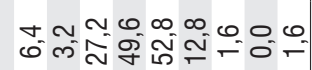 & 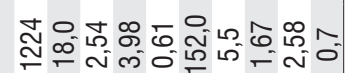 & \\
\hline & 엉 & 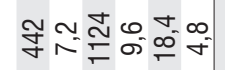 & $\begin{array}{l}\infty \\
\infty \\
0\end{array}$ & 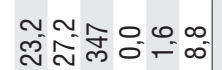 & 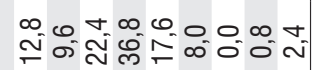 & 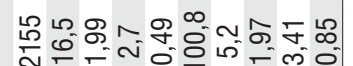 & \\
\hline 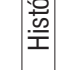 & $\dddot{I}$ & 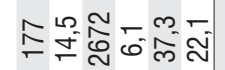 & 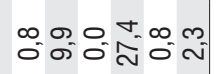 & 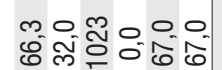 & 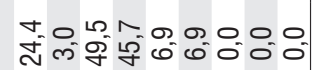 & ర్రి & \\
\hline & 峞 & 유용 & 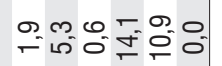 & 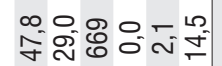 & 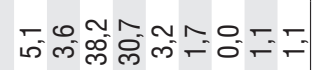 & 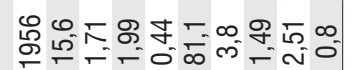 & \\
\hline & 覓 & 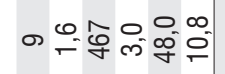 & 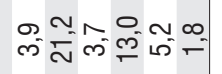 & 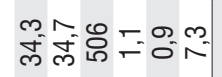 & 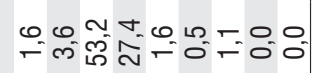 & 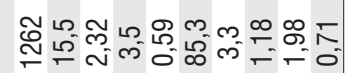 & \\
\hline & o & 总朵贯 & 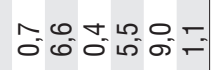 & 옹ำ & 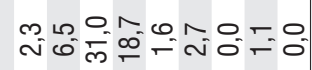 & 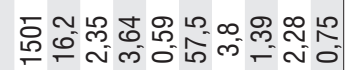 & \\
\hline & a & స̃ণ์ & 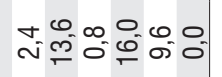 & กำ & 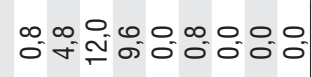 & 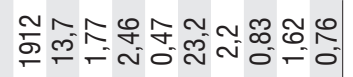 & \\
\hline & $\tilde{\Sigma}$ & 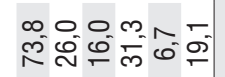 & 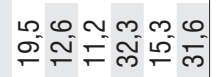 & $\begin{array}{l}m \infty n \\
\text { केస̃ }\end{array}$ & 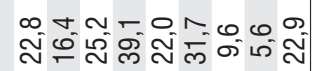 & 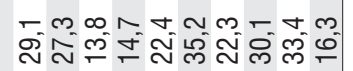 & \\
\hline & e & 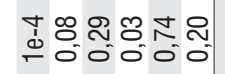 & 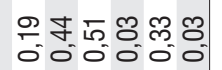 & $\begin{array}{l}\text { mo } \\
0 \\
0\end{array}$ & 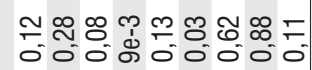 & 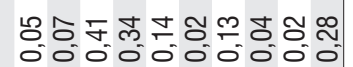 & \\
\hline & $\leq$ & 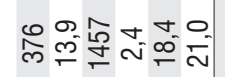 & 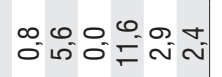 & 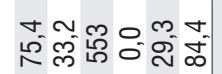 & 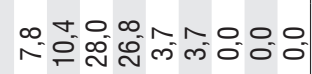 & 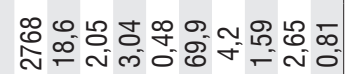 & \\
\hline 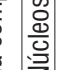 & $\leftleftarrows$ & 宗 & 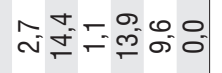 & $\stackrel{m}{\sim} \stackrel{\infty}{\sim}$ & & 舟 & \\
\hline & 하 & 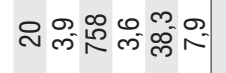 & 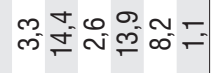 & 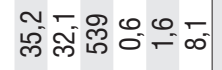 & & 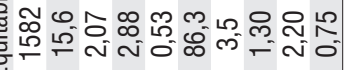 & \\
\hline & ت & 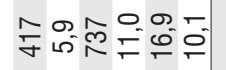 & 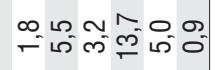 & 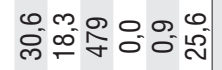 & कृष्ठ & ○. & \\
\hline & $\vec{\omega}$ & 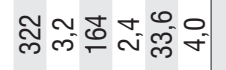 & 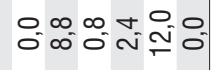 & 岛ず & & 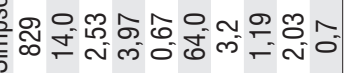 & \\
\hline & $\approx$ & 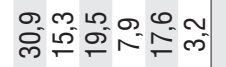 & $\begin{array}{l}\dot{\sigma} \\
\dot{m} \\
\dot{m}\end{array}$ & 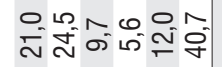 & & ñ & \\
\hline & $=$ & \%్ & 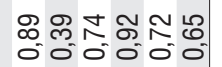 & $\begin{array}{l}1 \\
5\end{array}$ & & $=0$ & \\
\hline & ч & 足 & $\begin{array}{l}\infty \wedge=\infty \\
\sim \\
\sim\end{array}$ & 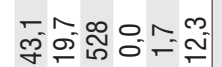 & & g & \\
\hline 㴔| & త & 勌 & 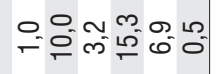 & 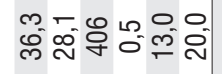 & & $F$ & \\
\hline & $\sum_{0}$ & 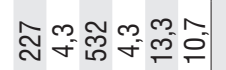 & స̃ & నొర్ & & is & \\
\hline & O & 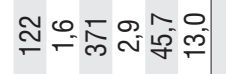 & 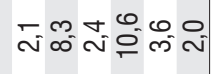 & 宓官 & & $=$ & \\
\hline & a & 守司心 & $\stackrel{\circ}{=} \stackrel{\infty}{\sim} 000000$ & & & 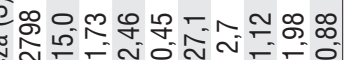 & \\
\hline & 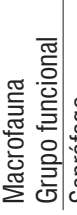 & 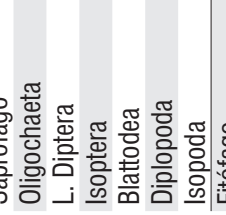 & 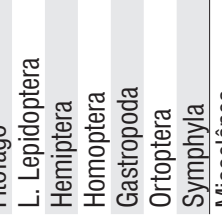 & 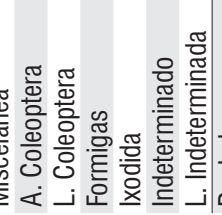 & 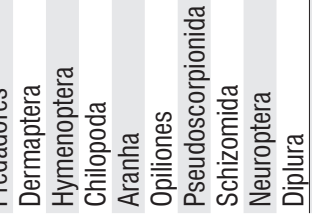 & 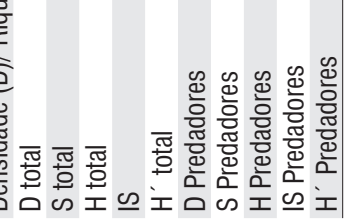 & \\
\hline
\end{tabular}


total na composição da macrofauna do solo com $15,8 \%$ no CP1, 12,8\% no CP2, 10,4\% no CP3 e 8,8\% no CP4. O CP1 representa um gradiente de abundância da maioria dos grupos sendo Invertebrados Indeterminados, Pseudoscorpiones, Opilionidae, Blattodea, Symphyla e Aranae os mais correlacionados com o CP1. O CP2 representa um gradiente de abundância de Hymenoptera (exceto Formicidae), Larvas Indeterminadas e Isoptera (Figura 2). O CP3 representa principalmente um gradiente de Oligochaeta, Isoptera e Isopoda opostos aos Aranae, Coleoptera, Schizomida e Ixodida, enquanto o CP4 representa um gradiente de Neuroptera, e Diplura opostos aos Formicidae, Gastropoda e Schizomida. A maioria das parcelas estão claramente separadas ao longo dos $\mathrm{CP}$ porém agrupamentos se destacam e serão detalhados através das ACP-C.

Análises entre-classes - A freqüência de fogo e o uso atual do solo (classes de idade e pastos) não apresentaram efeitos significativos sobre a composição da macrofauna $(\mathrm{P}>0,05)$ quando analisado com todos os núcleos geográficos com exceção de Oligochaeta e Larvas indeterminadas que foram significativamente diferentes entre os usos $(\mathrm{P}<0,05)$. Quando analisadas por núcleo, as classes de idade explicaram de 10 a $15 \%$ da variância da composição da macrofauna e seu efeito foi significativo para 4 núcleos $(\mathrm{P}<0,05)$, exceto São Luís $(\mathrm{P}=0,14)$. Dentro do núcleo Gurupi $\left(\mathrm{R}^{2}=10,4 \%\right.$; $\mathrm{P}=0,0007)$, as capoeiras e florestas se separaram ao longo do CP1: as capoeiras de sete anos (C7) e as florestas (F) foram correlacionadas positivamente com CP1, junto com Diplopoda, Oligochaeta e Isopoda e, as capoeiras de três anos (C3) e onze anos (C11) foram correlacionadas negativamente com CP1, junto com Schizomida, Gastropoda e Isopoda. O CP2 separou as capoeiras das florestas, correlacionadas positivamente com esse eixo junto com Oligochaeta, Formicidae, Dermaptera e Larvas de Diptera (Figura 3A e B).

No núcleo do Livramento $\left(\mathrm{R}^{2}=14,8 \% ; \mathrm{P}=0,01\right)$, as áreas de capoeiras altas (CA) e as de florestas (F) se separaram das áreas de capoeiras médias (CM) e baixas (CB) que ficaram agrupadas. As CA se correlacionaram positivamente com CP1 junto com Oligochaeta, Larvas Indeterminadas, Dermaptera e Homoptera enquanto as $\mathrm{CM}$ e CB se correlacionaram negativamente com CP1 junto com Opilionidae, Indeterminados, Diplura e Neuroptera. As florestas se separaram das capoeiras ao longo de CP2, positivamente correlacionadas com esse eixo junto aos Formicidae, Symphyla e Hemiptera principalmente (Figura 3C e D).

No núcleo de Igarapé-Açu $\left(\mathrm{R}^{2}=11 \% ; \mathrm{P}=0,0001\right)$, o CP1 separou as CA das CM e CB. As CA foram positivamente correlacionadas com o CP1 junto com Isoptera, Indeterminados, Formicidae e Diplopoda principalmente. O CP2 separou as $\mathrm{CM}$ e $\mathrm{CB}$, as $\mathrm{CM}$ sendo positivamente correlacionadas com o eixo junto com Coleoptera adultos, Oligochaeta, Larvas de Diptera e Ortoptera, enquanto as $\mathrm{CB}$ foram negativamente correlacionadas com o eixo junto

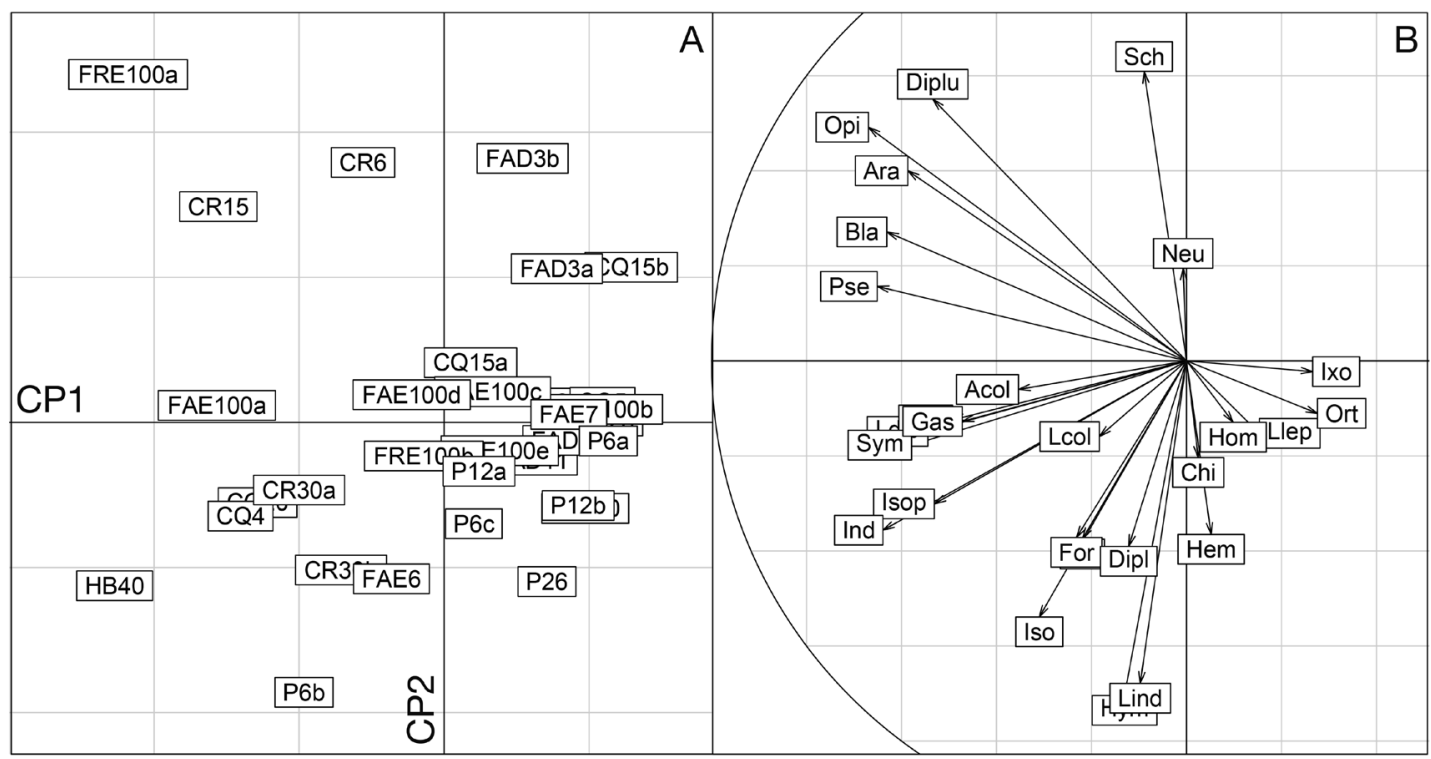

Figura 2. Análise de componentes principais dos grupos de macrofauna do solo de uma cronoseqüência de capoeiras, matas e pastos no Centro de Endemismo Belém. A) Diagrama com todas as parcelas estudadas (legenda das siglas na Tabela 1; B) Círculo de correlações (Oli=0ligochaeta, ACol=Coleoptera adulto, $\mathrm{LCol}=$ Larva coleoptera, LDip=Larva diptera, For=Formicidae, Iso=Isoptera, Bla=Blattodea, Diplu=Diplura, Ort=Orthoptera, Hem=Hemiptera, Hom =Homoptera, $\mathrm{Chi}=$ Chilopoda, $\mathrm{Dipl}=$ Diplopoda, $\mathrm{Isop}=\mathrm{Isopoda}, \mathrm{Ara}=$ Aranae, $\mathrm{Opi}=$ Opilionidae, $\mathrm{Pse}=$ Pseudoscorpiones, $\mathrm{Sch}=\mathrm{Schizomidae}$, Gas=Gastropoda, Lind=Larva Indeterminada, Ixo=Ixodidae, Der=Dermaptera, Neu=Neuroptera). Valores próprios dos eixos: $\mathrm{CP} 1=15,8 \%$ (horizontal), CP2=12,8\% (vertical). 


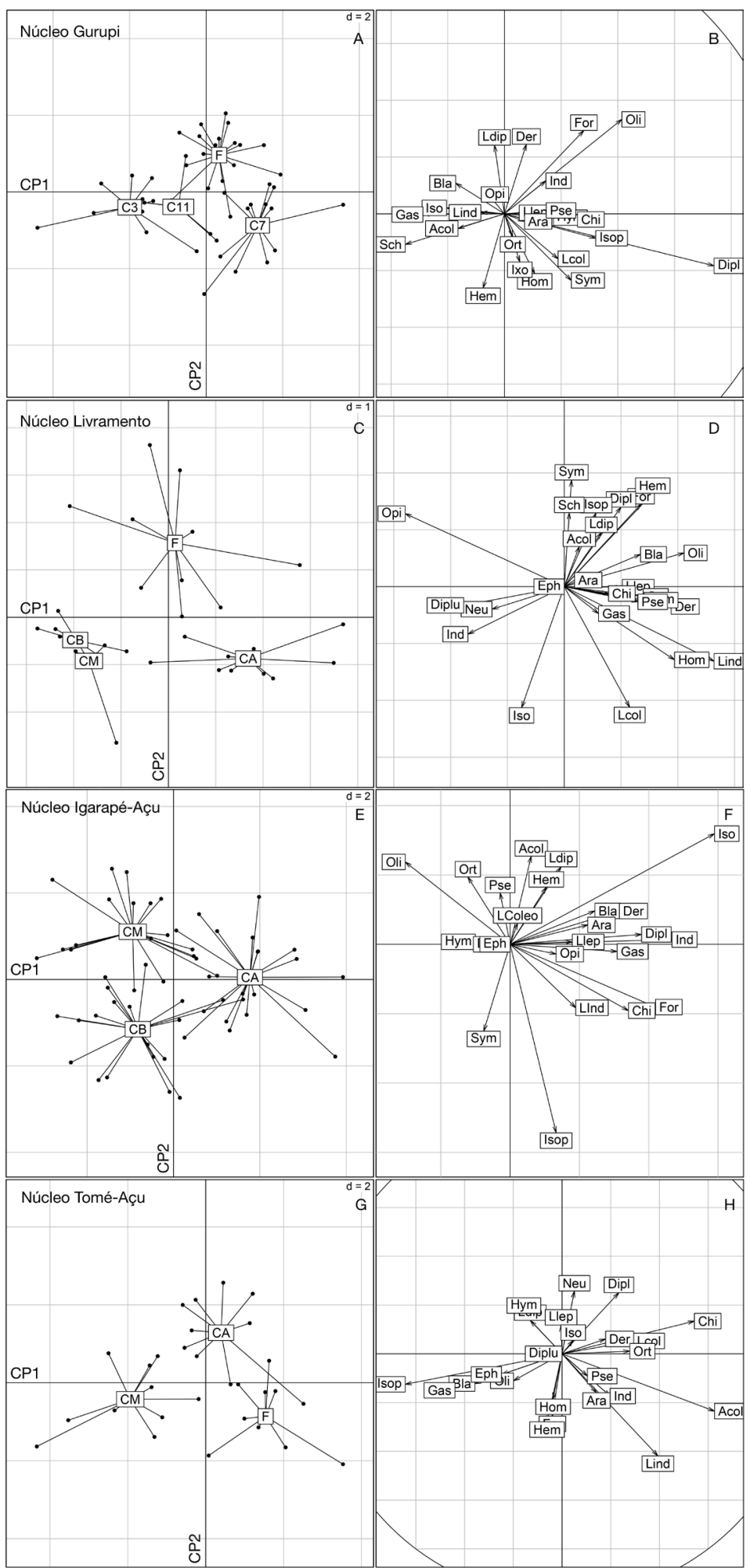

Figura 3. Análise de componentes principais entre-classes dos grupos de macrofauna do solo de uma cronoseqüência de capoeiras e matas no núcleo de Gurupi (A e B), Livramento (C e D), Igarapé-Açú (E e F) e Tomé-Açú (G e H). A esquerda apresentam-se os diagramas das parcelas classificadas por uso atual dentro dos núcleos geográficos (A, C, E e G; legenda das classes no texto) e a direita os círculos de correlações dos grupos taxonômicos da macrofauna (B, D, F e H; legenda na Figura 2). 0 uso atual do solo explica 10,4\% da variância na composição da macrofauna no Núcleo Gurupi $(P=0,0007), 14,8 \%$ no Livramento ( $P=0,01), 10,8 \%$ em Tomé-Açú $(P=0,0003)$ e 11\% em Igarapé-Açú $(P=0,0001)$. Valores não significativos para o núcleo São Luis $(P=0,14)$. 
com Isopoda, Symphyla, Chilopoda, Formigas e Larvas Indeterminadas (Figura 3E e F).

No núcleo de Tomé-Açu $\left(\mathrm{R}^{2}=10,8 \% ; \mathrm{P}=0,0003\right)$, o $\mathrm{CP} 1$ separou as florestas, as áreas de capoeiras altas e as áreas de capoeiras médias. As $\mathrm{F}$ e as CA foram positivamente correlacionadas com CP1, junto com Coleoptera, Chilopoda e Larvas indeterminadas. As CA se separaram das outras classes ao longo do $\mathrm{CP} 2$ e se correlacionaram positivamente com esse eixo junto com Neuroptera, Diplopoda e Hymenoptera principalmente (Figura 3G e H).

Os táxons mais sensíveis a idade da capoeira nos núcleos foram Diplopoda (Gurupi, São Luís, Igarapé-Açu), Oligochaeta (Gurupi, Livramento, São Luís, Igarapé-Açu), Isopoda (Gurupi, Tomé-Açu, Igarapé-Açu), Formicidae (Gurupi, Livramento, Igarapé-Açu), Larvas indeterminadas (Livramento, São Luís, Tomé-Açu) e Dermaptera (Livramento, Igarapé-Açu). Diplopoda, Oligochaeta, Isopoda, Formicidae e Dermaptera foram associados às florestas e capoeiras altas no Gurupi e Livramento enquanto Diplopoda e Dermaptera permaneceram associados às capoeiras altas em Tomé-Açu e Igarapé-Açu. Oligochaeta e as Formigas se associaram às capoeiras médias e baixas em São Luís e Tomé-Açu. Oligochaeta se associaram às capoeiras médias também em Igarapé-Açu. Isopoda ficaram associados às capoeiras médias e baixas em Tomé-Açu e Igarapé-Açu.

Os núcleos geográficos explicaram $26,1 \%$ da variância na composição da macrofauna ( $\mathrm{P}=0,0001)$. Igarapé-Açu (IA) e a Ilha do Livramento $(\mathrm{Li})$ se separaram das demais regiôes no CP1. Os invertebrados indeterminados, Symphyla, Larvas de diptera, Larvas indeterminadas e Coleoptera (adultos) correlacionaram-se positivamente com CP1 e IgarapéAçu (IA), enquanto Ortoptera, Hemiptera, Neuroptera e Diplopoda correlacionaram-se com Gurupi $(\mathrm{Gu})$, São Luís (SL) e Tomé-Açu (TA). Gu, SL e TA se separam no CP2, $\mathrm{Gu}$ ficou correlacionado positivamente com $\mathrm{CP} 2$ junto com Aranae, Chilopoda, Blattodea e Coleoptera (larvas) e TA se correlacionou negativamente junto com Oligochaeta, Pseudoscorpionida e Isopoda (Figura 4).

O histórico de uso explicou $31,7 \%$ da variância na composição da macrofauna ( $\mathrm{P}=0,0005)$ (Tabela 1). Dermaptera, Blattodea e Pseudoscorpiones foram os grupos mais correlacionados com $\mathrm{CP} 1$ junto com as florestas de restinga exploradas (FRE), capoeiras de restinga (CR) e áreas historicamente cultivadas com Hevea brasiliensis (HB). Orthoptera e Hemiptera foram negativamente correlacionados com CP2 junto com a floresta amazônica sem intervenção (FA), os pastos (P) e as florestas amazônicas degradadas (FAD).

Chilopoda, Aranae e Larvas de coleoptera correlacionaramse positivamente com $\mathrm{CP} 2$ junto com $\mathrm{FAD}$, enquanto Oligochaetas, Isopoda e Isoptera correlacionaram-se negativamente com CP2 junto com P, as parcelas de "cortequeima" (CQ) e FA (Figura 5). As parcelas de uso menos intenso (FRE, CR, HB) mostraram a comunidade de predadores mais abundante (Dermaptera, Pseudoscorpiones, Diplura, Opilionidae, Aranae), as parcelas de floresta amazônica explorada (FAE) mostraram uma comunidade de predadores similar às FRE, CR e HB mas, menos abundante, as FAD mostraram uma comunidade de predadores diferenciada (Larvas de Coleoptera, Schizomida e Chilopoda)

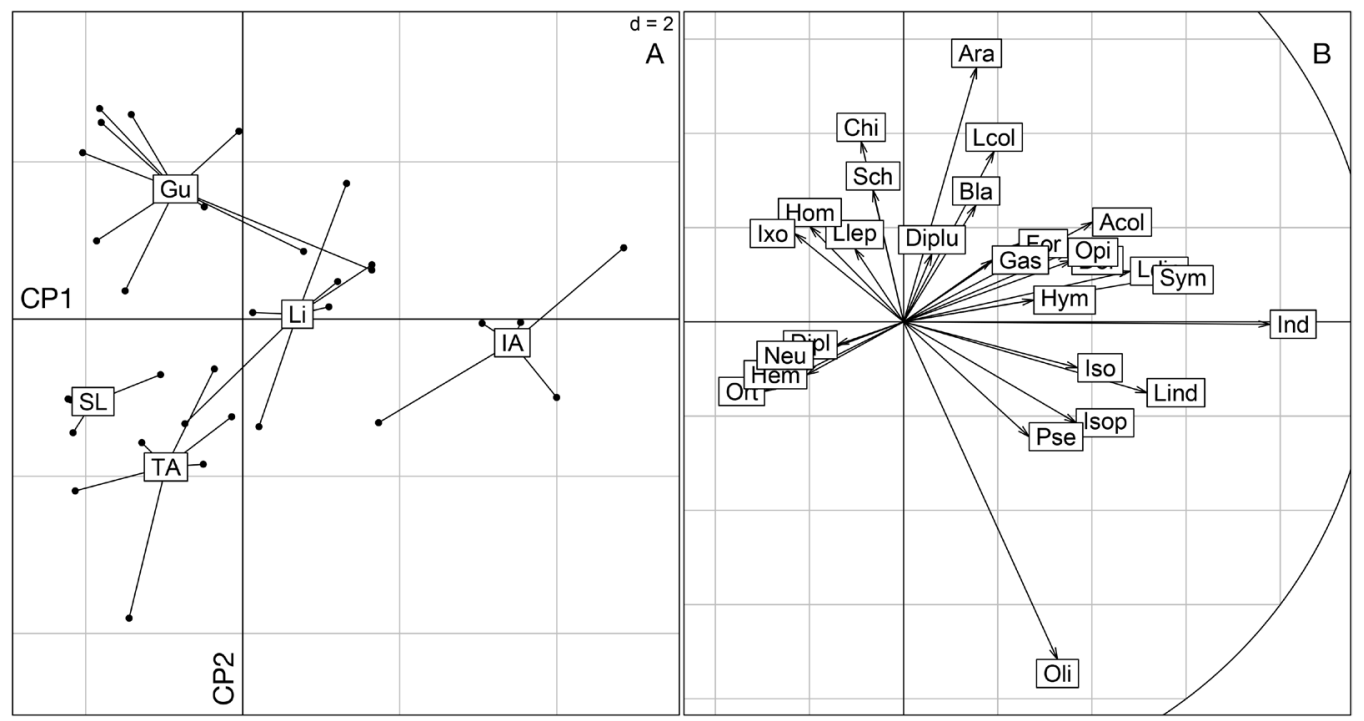

Figura 4. Análise de componentes principais entre-classes dos grupos de macrofauna do solo de uma cronosequiência de capoeiras e matas em 5 núcleos: A) Diagrama dos núcleos geográficos classificados (Gu: Gurupi; Li: Livramento; SL: São Luís; TA: Tomé-Açu; IA: Igarapé-Açu); B) Círculo de correlações (legenda na Figura 2). Os núcleos explicam $26,1 \%$ da variância na composição da macrofauna ( $P=0,0001)$. 


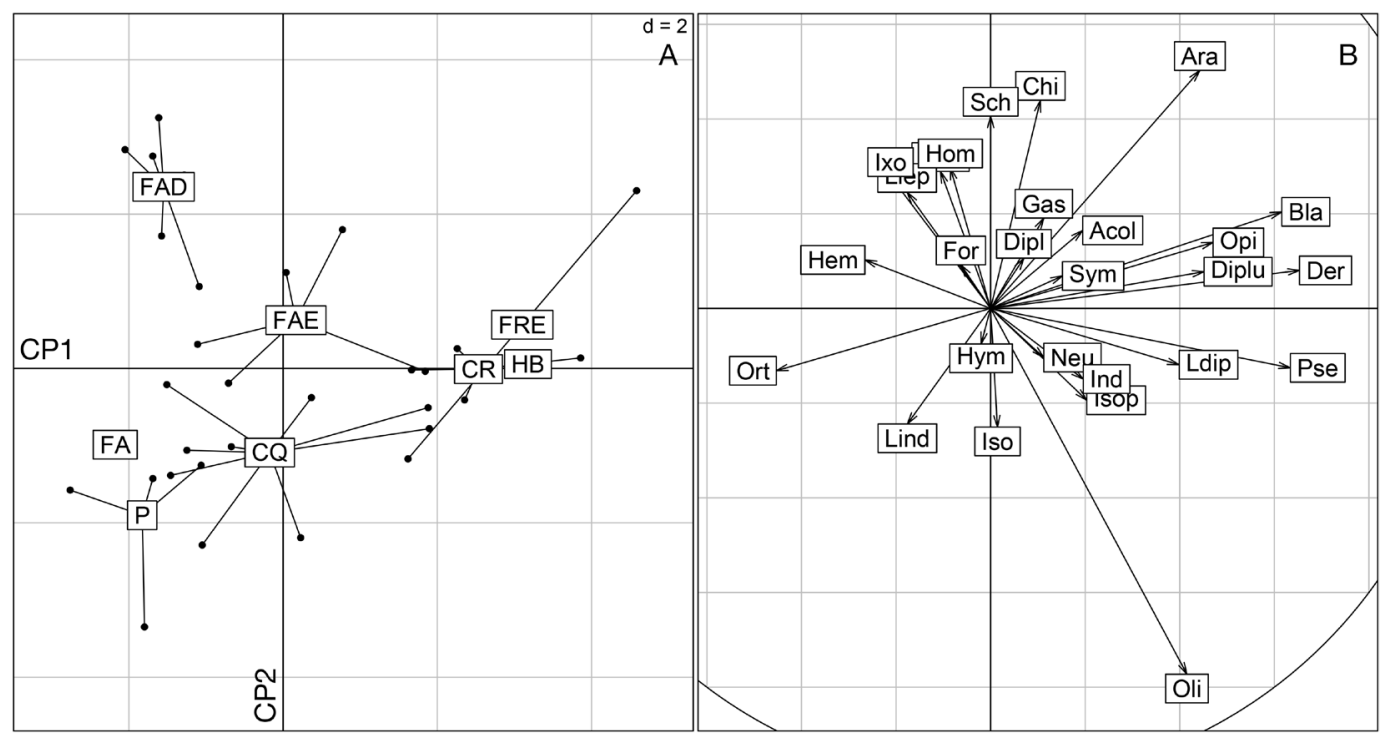

Figura 5. Análise de componentes principais entre-classes dos grupos de macrofauna do solo de uma cronoseqüência de capoeiras, matas e pastos no Centro de Endemismo Belém classificadas por histórico de uso. A) Diagrama das parcelas classificadas por histórico de uso (legenda das classes na Tabela 1); B) Círculo de correlações (legenda na Figura 2). 0 histórico de uso explica 31,7\% da variância na composição da macrofauna $(P=0,0002)$.

enquanto as parcelas CQ se caracterizaram por populaçóes elevadas de Oligochaeta e Larvas Indeterminadas (algumas delas com abundância muito elevada de Isoptera e Isopoda) e as parcelas $\mathrm{P}$ pela abundância de Orthoptera, Hemiptera, Larvas Indeterminadas e Oligochaetas (Figura 5).

Coleoptera, Chilopoda e Indeterminados foram os táxons mais correlacionados com o $\mathrm{CP} 3$ juntos com os $\mathrm{CQ}$ e o $\mathrm{HB}$, enquanto Gastropodas, Formicidae, Blattodea e Larvas de Lepidoptera foram negativamente correlacionados com CP3 junto com as florestas (FAE, FA e FAD), CR, FRE e P. Isoptera, Larvas de Coleoptera, Gastropoda e Formicidae foram os táxons mais correlacionados com CP4, juntos com CR, HB e FAE, enquanto Schizomida, Symphyla e Isopoda se correlacionaram negativamente com esse eixo, junto com FRE e CQ (Figura 5).

Quando testado sobre os táxons predadores unicamente (Dermaptera, Chilopoda, Aranae, Opilionidae, Pseudoscorpiones, Schizomida, Neuroptera e Diplura), o histórico de uso explicou $36,1 \%$ da variância $(P=0,009)$. Esse efeito foi maior ainda sobre a densidade, riqueza, diversidade de Shannon-Wiener e equitatividade de Pielou dos predadores com $\mathrm{R}^{2}=44,4 \%(\mathrm{P}=0,003)$.

\section{DISCUSSÃO}

Como mostrado por Rossi et al. (2006), a amostragem de cinco monólitos TSBF por parcela permitiu coletar uma fraçáo elevada da diversidade total de táxons (> 77\%) para todos os usos de solo com exceçáo dos pastos (68\%). A alta heterogeneidade e a ocorrência de espécies raras nos solos tropicais impede geralmente a saturação da curva do coletor e exige uma adequação do esforço de amostragem com os objetivos de cada estudo e a disponibilidade de máo de obra. Nesse estudo de ampla distribuição geográfica, o esforço amostral foi reduzido ao mínimo determinado por Rossi et al. (2010) e confirmou a validade da abordagem para o CEB considerando que uma amostragem mais completa da diversidade da biota do solo de cada parcela exigiria 20 diaspessoa (Bignell 2009).

Embora o Centro de Endemismo Belém seja a região mais desmatada da Amazônia, os resultados indicam que o mosaico criado na paisagem pela agricultura familiar de corte-queima com capoeiras em diferentes estágios de pousio tem um potencial muito grande para a conservação da biodiversidade do solo (Holloway e Stork 1991; Rousseau et al. 2010). Para permitir o uso produtivo das áreas desmatadas e reduzir a pressão sobre os remanescentes florestais e as capoeiras antigas é imprescindível conservar e usar a macrofauna do solo de maneira a otimizar os processos de restauração da qualidade do solo e os serviços ambientais associados (Lavelle et al. 2006; Mcneely e Scherr 2008).

Identificamos que o histórico de uso do solo foi o fator que mais explicou a composição da macrofauna mostrando que esse efeito pode perdurar pelo menos duas décadas, o que foi verificado recentemente por Gomes e Luizão (2011) com os nutrientes das folhas e do solo em áreas de capoeiras da Amazônia Central. O efeito da intensificação agrícola sobre as comunidades de invertebrados do solo está bem documentado 
e mostra uma redução da abundância e diversidade diretamente relacionada com o nível de intensificação (Decaënz e Jimenez 2002), no entanto o efeito do histórico de uso está pouco documentado (Foster et al. 2003; Liiri et al. 2012) ou sem documentação no caso da Amazônia.

De acordo com Foster et al. (2003), o efeito de práticas agrícolas intensivas pode perdurar por séculos, enquanto Liiri et al. (2012) verificaram em microcosmos que o uso intensivo do solo afeta a provisão de serviços ambientais e que, no curto prazo, mesmo a restauração artificial de uma comunidade complexa de macrofauna náo alivia os efeitos do uso intensivo. Apesar de oriundos de ambientes muito diferentes, esses resultados apontam conclusôes similares às desse estudo, o que sugere que o efeito do histórico de uso tem impactos profundos e duradouros no funcionamento do solo que podem ser determinantes para o sucesso da restauraçáo de áreas degradadas ou da implantação de práticas agrícolas mais sustentáveis.

Os resultados disponíveis na Amazônia sobre o histórico do uso do solo são recentes e só contemplam comunidades vegetais. Eles mostram, na Amazônia Central, que o acúmulo de biomassa e a riqueza de espécies arbóreas é significativamente reduzido em capoeiras com maior tempo de pastagem (Wandelli 2008) e que áreas desmatadas e sem uso subseqüente são dominados por Cecropia enquanto aquelas usadas para pasto são dominados por Vismia (Norden et al. 2011). Tais impactos na vegetaçáo podem influenciar diretamente a abundância e diversidade da macrofauna através de variaçôes na quantidade e qualidade da serrapilheira depositada (Sayer et al. 2010).

Nossos resultados mostram que o efeito do histórico afeta a composição da macrofauna da seguinte forma (Figura 5): a medida que o uso aumenta de intensidade (ao longo de $\mathrm{CP} 1$ e depois de $\mathrm{CP} 2$ ) a comunidade de predadores diminui em abundância e diversidade. Assim, o efeito do histórico é similar ao efeito da intensificação agrícola (Decaëns e Jimenez 2002) e confirma seu efeito profundo e duradouro sobre as comunidades de invertebrados do solo. De fato, populaçōes de predadores abundantes e diversas indicam um fluxo normal de energia dentro das comunidades (Neutel et al. 2002) ou seja, o funcionamento normal do solo.

Nesse nível de identificação, a comunidade dos predadores já se mostrou eficiente indicadora de alteraçôes significativas no funcionamento do solo no trópico úmido (Rousseau et al. 2012) e pode servir de alerta para quem monitora a qualidade do solo. A parcela de floresta primária caracteriza-se por populaçôes baixas de predadores e conseqüentemente é a única que não segue esse padráo geral, o que pode ser explicado pelo processo de "retrogressão" no qual a sucessão vegetal pára de se complexificar após algumas décadas de sucessão ou pode levar à uma redução da diversidade e da produção vegetal
(Wardle 2006) que se repercute sobre os invertebrados e os micro-organismos do solo (Chauvat et al. 2003).

A ausência de efeito do uso atual do solo sobre a macrofauna pode ser explicada pela alta variabilidade entre os núcleos e ao fato que não foi possível encontrar todas as classes de idade dentro de cada núcleo, exceto no Livramento. O efeito significativo do uso atual dentro dos núcleos (exceto Sáo Luís) e o maior efeito desse fator na ilha do Livramento apóia essa hipótese.

A variabilidade encontrada na escala do CEB confirma a necessidade de multiplicar os estudos locais para determinar com precisão o peso das variaçóes do clima, solo e tipo de vegetação em comparação com os usos do solo e as práticas de manejo. A comunidade de macrofauna, como a comunidade vegetal na Amazônia (Silva et al. 2013), apresenta variaçóes locais determinantes para o funcionamento do solo e sua restauração. É de primeira importância intensificar o esforço amostral na regiáo para entender como esses invertebrados respondem aos gradientes pan-amazônicos de clima, solo e vegetação (Davidson et al. 2012) para planejar o uso do solo e responder aos desafios do desmatamento e das mudanças climáticas.

Outro ponto chave que pode explicar o efeito moderado das classes de idade é a baixa resoluçáo de identificação dos invertebrados do solo. Por causa da alta diversidade dos solos tropicais combinada com a falta de especialistas e estudos descrevendo os invertebrados do solo em detalhe (nível de gênero ou espécies), o nível de identificação apresentado nesse estudo é bem aceito porque proporciona informaçôes essenciais sobre o funcionamento do solo e está ao alcance de todos (Lavelle et al. 2003; Moço et al. 2010; Sayer et al. 2010). No entanto, Nahmani et al. (2006) já mostraram que a identificação em nível de espécie é o mais preciso para fins de bioindicação, apesar das dificuldades de identificação e do tempo requerido.

Os grupos sensíveis à idade das áreas de capoeiras são saprófagos, com exceção de Dermapteras (saprófagos e predadores), e foram mais abundantes nas matas e áreas de capoeiras altas em pelo menos dois núcleos. Isso sugere que a abundância desses grupos responde ao aumento da biomassa vegetal e aporte de serrapilheira ao solo (Sayer et al. 2010). $\mathrm{O}$ fato de Oligochaeta, Isopoda e Formicidae não seguirem esse padrão para os núcleos de São Luís, Tomé-Açu e IgarapéAçu pode ser explicado pela falta de uma classe de idade. Oligochaeta, Isopoda e Formicidae são grupos considerados como engenheiros do ecossistema (Lavelle et al. 2006; Jouquet et al. 2006), no sentido que eles modificam o ambiente físico dos demais habitantes do solo, e já estáo sendo utilizados como indicadores da qualidade do solo. A abundância e diversidade de minhocas são utilizadas para monitorar a qualidade do solo e o impacto de práticas agrícolas em ambientes temperados 
(Paoletti 1998). Nos solos tropicais a identificação das espécies é muito mais complexa e a alta abundância da espécie invasora Pontoscolex corethrurus pode indicar uma degradação severa do solo (Chauvel et al. 1999).

Isopodas, por seu papel fundamental na ciclagem dos nutrientes, estáo sendo usados como indicadores de perturbação antropogênica (Buchs 2003) e sua abundância total já foi relatada como sensível a perturbação, mas a composição específica revelou ser um indicador mais sensível (Magrini et al. 2011). As formigas também são amplamente utilizadas como indicadores ambientais (Pais e Varanda 2010; Rousseau et al. 2010), no entanto sua abundância ou diversidade total são raramente indicadores eficientes por causa da alta adaptabilidade das comunidades onde espécies se substituem frente às mudanças do ambiente. Conseqüentemente, a composição específica ou os grupos funcionais de formigas são indicadores mais eficientes (Rousseau et al. 2010).

Outro fator que pode explicar o efeito moderado da cronoseqüencia é o processo de "retrogressão" mencionado anteriormente. Como as cronoseqüências desse estudo são dominadas por áreas de capoeiras jovens e florestas antigas, esse processo natural pode explicar similaridades inesperadas entre os extremos, principalmente para as variáveis de abundância total e diversidade.

\section{CONCLUSÕES}

A identificação da macrofauna do solo por grandes grupos taxonômicos se mostrou sensível ao efeito do histórico de uso do solo e identificou comunidades significativamente distintas entre os núcleos estudados (micro-regióes), havendo nessa escala efeito da cronosequência de capoeiras e florestas. A intensidade do uso do solo levou a redução da abundância e da riqueza de predadores, indicando alteraçóes significativas no funcionamento do solo. Esses resultados mostram um efeito duradouro da degradaçáo do solo sobre a macrofauna e conseqüentemente sobre suas funçôes ecológicas. Dessa forma, o estudo e a conservação da macrofauna do solo em remanescentes florestais mostra-se como uma prioridade nas fronteiras antigas da Amazônia já que as funçôes ecológicas perdidas em poucos anos de uso intensivo precisam de décadas para serem restauradas.

\section{AGRADECIMENTOS}

Este projeto foi financiado pela Fundaçáo de Amparo à Pesquisa do Maranháo (FAPEMA), pelo Conselho Nacional de Pesquisa (CNPq) e pelo Programa de Pesquisa em Biodiversidade na Amazônia (PPBio). Agradecemos o apoio logístico recebido do Instituto Chico Mendes de Conservação da Biodiversidade (ICMBio) na Rebio Gurupi e da Natura e
Embrapa em Tomé-Açú. Somos gratos a Cooperativa Agrícola Mista de Tomé-Açu (CAMTA) e diversos agricultores os quais permitiram a realização da pesquisa em suas terras e aos estudantes da Universidade Estadual do Maranhão (UEMA) e ajudantes de campo que auxiliaram na extraçáo manual da macrofauna do solo. Daniel Santos elaborou o mapa das parcelas estudadas.

\section{BIBLIOGRAFIA CITADA}

Almeida, A.S.; Vieira, I.C.G. 2010. Centro de endemismo Belém: status da vegetaçáo remanescente e desafios para a conservação da biodiversidade e restauraçáo ecológica. Revista de Estudos Universitários, 36: 95-111.

Anderson, J. D.; Ingram, J. S. I. 1993. Tropical soil biology and fertility: a handbook of methods, 2 ed. CAB International, Wallingford, 1993. $171 \mathrm{p}$.

Bignell, D.E. 2009. Towards a universal sampling protocol for soil biotas in the humid tropics. Pesquisa Agropecuária Brasileira, 44: 825-834.

Blouin, M.; Hodson, M.E.; Delgado, E.A.; Baker, G.; Brussaard, L.; Butt, K.R.; et al. 2013. A review of earthworm impact on soil function and ecosystem services. European Journal of Soil Science, 64: 161-182.

Buchs, W. 2003. Biodiversity and agri-environmental indicatorsgeneral scopes and skills with special reference to the habitat level. Agriculture, Ecosystems and Environment, 98: 35-78.

Chauvat, N.; Zaitsev, A.S.; Wolters, V. 2003. Succecional changes of collembola and soil microbiota during forest sucession. Oecologia, 137: 269-276.

Chauvel, A.; Grimaldi, M.; Barros, E.; Blanchart, E.; Sarrazin, M.; Lavelle, P. 1999. Pasture degradation by an Amazonian earthworm. Nature, 389: 32-33.

Chessel, D.; Dufour, A.B.; Thioulouse, J. 2004. The ade4 package - I: One-table methods. R News, 4: 5-10.

Colwell, R.K. 2013. EstimateS: Statistical estimation of species richness and shared species from samples. Version 9. Persistent URL < purl.oclc.org/estimates>, Acesso em18/11/13.

Davidson, E.A.; Araújo, A.C.; Artaxo, P.; Balch, J.K.; Brown, I.F.; Bustamante, M.M.C.; et al. 2012. The Amazon basin in transition. Nature, 481: 321-328.

Decaëns, T.; Jiménez, J.J. 2002. Earthworm communities under an agricultural intensification gradient in Colombia. Plant and Soil, 240: 133-143.

Foster, D.; Swanson, F.; Aber, J.; Burke, I.; Brokaw, N.; Tilman, D.; et al. 2003. The importance of land-use legacies to ecology and conservation. Bioscience, 53: 77-88.

Gomes, A.C.S.; Luizão, F.J. 2011. Leaf and soil nutrients in a cronosequence of second-growth forest in Central Amazonia: implications for restoration of abandoned lands. Restoration Ecology, 20: 339-345.

Gongalsky, K.B.; Malmström, A.; Zaitsev, A.S.; Shakhab, S.V.; Bengtsson, J.; Persson, T. 2012. Do burned areas recover from 
inside? An experiment with soil fauna in a heterogeneous landscape. Applied Soil Ecology, 59: 73- 86

Holloway, J.D.; Stork, N.E. 1991. The dimensions of biodiversity: The use of invertebrates as indicators of human impact. In: Hawksworth, D.L. (Ed.). The Biodiversity of Microorganisms and Invertebrates: Its Role in Sustainable Agriculture. CAB International, London, p. 37-62.

Jouquet, P.; Dauber, J.; Lagerlöf, J.; Lavelle, P.; Lepage, M. 2006. Soil invertebrates as ecosystem engineers: Intended an accidental effects on soil and feedback loops. Applied Soil Ecology, 32: 153-164

Lavelle, P.; Senapati, B.; Barros, E. 2003. Soil macrofauna. In: Schroth, G.; Sinclair, F.L. (Ed.). Trees, Crops and Soil Fertility. CABI Publishing, Wallingford, p. 303-304.

Lavelle, P.; Decaëns, T.; Aubert, M.; Barot, S.; Blouin, M.; Bureau, F.; et al. 2006. Soil invertebrates and ecosystem services. European Journal of Soil Biology, 42: 3-15.

Liiri, M.; Häsä, M.; Haimi, J.; Setälä, H. 2012. History of landuse intensity can modify the relationship between functional complexity of the soil fauna and soil ecosystem services - A microcosm study. Applied Soil Ecology, 55: 53- 61.

Magrini, M. J.; Freitas, A. V. L.; Uehara-Prado, M. 2011. The effects of four types of anthropogenic disturbances on composition and abundance of terrestrial isopods (Isopoda: Oniscidea). Zoologia, 28: 63-71.

Mathieu, J.; Rossi, J.P.; Mora, P.; Lavelle, P.; Da S. Martins, P.F.; Rouland, C.; et al. 2005. Recovery of soil macrofauna communities after forest clearance in Eastern Amazonia, Brazil. Conservation Biology, 19: 1598-1605.

Mcneely, J.A.; Scherr, S.J. 2008. Ecoagricultura: Estrategias para alimentar al mundo y salvar la biodiversidad silvestre. InterAmerican Institute for Cooperation in Agriculture San Jose, Costa Rica, 2008, 364p.

MEA (Millennium Ecosystem Assessment). 2005. Ecosystems and human well-being. A framework for assessment. Island Press, Washington, 2005, 948 p.

Moço, M.K.S.; Gama-Rodrigues, E.F.; Gama-Rodrigues, A.C.; Machado, R.C.R.; Baligar, V.C. 2010. Relationships between invertebrates communities, litter quality and soil attributes under different cacao agroforestry systems in the south of Bahia, Brazil. Applied Soil Ecology, 46, 347-354.

Moura, E.G.; Moura, N.G.; Marques, E.S.; Pinheiro, K.M.; Costa Sobrinho, J.R.S.; Aguiar, A.C.F. 2009. Evaluating chemical and physical quality indicators for a structurally fragile tropical soil. Soil Use and Management, 25:368-375.

Nahmani, J.; Lavelle, P.; Rossi, J.P. 2006. Does changing the taxonomical resolution alter the value of soil macroinvertebrates as bioindicators of metal pollution? Soil Biology and Biochemistry, 38: 385-396.

Neutel, A.M.; Heesterbeek J.A.P.; De Ruiter, P.C. 2002. Stability in Real Food Webs:Weak Links in Long Loops. Science, 296: 1120-1123.

Norden, N.; Mesquita, R.C.G.; Bentos, T.V.; Chazdon, R.L.; Williamson, G.B. 2011. Contrasting community compensatory trends in alternative successional pathways in central Amazonia. Oikos, 120: 143-151

Pais, M.P.; Varanda, E.M. 2010. Arthropod Recolonization in the Restoration of a Semideciduous Forest in Southeastern Brazil. Neotropical Entomology, 39: 198-206.

Paoletti, M.G.; Sommaggio, D.; Favretto, M.R.; Petruzzelli, G.; Pezzarossa, B.; Barbafleri, M. 1998. Earthworms as useful bioindicators of agroecosystem sustainability in orchards and vineyards with different inputs. Applied Soil Ecology, 10: 137-150.

R Development Core Team. 2009. R: A language and environment for statistical computing. R Foundation for Statistical Computing,Vienna, Austria. http://www.R-project.org. Acesso em10/12/12.

Rossi, J.P.; Celini, L.; Mora, P.; Mathieu, J.; Lapied, E.; Nahmani, J.F.; et al. 2010. Decreasing fallow duration in tropical slash and burn agriculture alters soil macroinvertebrate diversity: A case study in southern French Guiana. Agriculture, Ecosystems and Environment, 135: 148-154.

Rossi, J.-P.; Mathieu, J.; Cooper, M.; Grimaldi, M. 2006. Soil macrofaunal biodiversity in Amazonian pastures: Matching sampling with patterns. Soil Biology and Biochemistry, 38: 2178-2187.

Rousseau, G.X.; Silva, P.R.S.; De Carvalho, C.J.R. 2010. Earthworms and arthropods as soil health indicators in traditional and no-fire agro-ecosystems from Eastern Amazon. Acta Zoologica Mexicana. Número especial 2: 117-134.

Rousseau, G.X.; Deheuvels, O.; Rodriguez Arias, I.; Somarriba, E. 2012. Indicating soil quality in cacao-based agroforestry systems and old-growth forests: The potential of soil macrofauna assemblage. Ecological Indicators, 23: 535 - 543.

Sayer, E.J.; Sutcliffe, L.M.E.; Ross, R.I.C.; Tanner, E.V.J. 2010. Arthropod Abundance and Diversity in a Lowland Tropical Forest Floor in Panama: The Role of Habitat Space vs. Nutrient Concentrations. Biotropica, 42: 194-200.

Silva, F.B.; Shimabukuro, Y.E.; Aragão, L.E.O.C; Anderson, L.O.; Pereira, G.; Cardozo, F.; et al. 2013. Large-scale heterogeneity of Amazonian phenology revealed from 26-year long AVHRR/NDVI time-series. Environmental Research Letters, 8: 24011-24024.

Silva, J.M.C.; Rylands, A.B.; Fonseca, G.A.B. 2005. O destino das áreas de endemismo da Amazônia. Megadiversidade, 1: 124-131.

Wandelli, E.V. 2008. Estoques de biomassa em diferentes cenários de uso da terra ao norte de Manaus, Amazônia Central brasileira. Dissertação de Doutorado, Instituto Nacional de Pesquisas da Amazônia/ Universidade do Amazonas, Manaus, Amazonas. 162p.

Wardle, D.A. 2006. The influence of biotic interactions on soil biodiversity. Ecology letters, 9: 870 -886.

Recebido em 01/07/2013

Aceito em 07/03/2014 


\section{APÊNDICE}
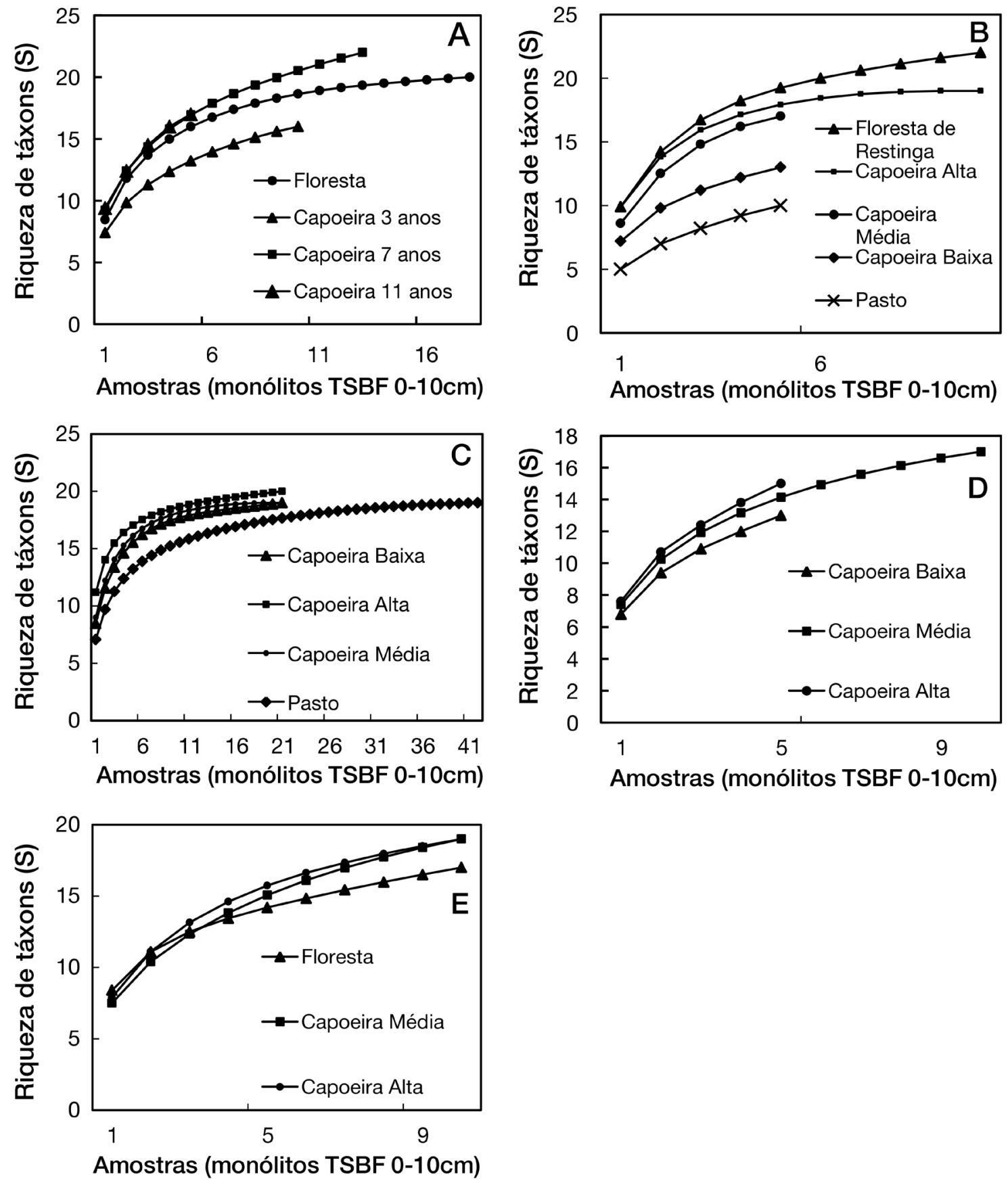

Figura 1A. Curva de acumulação de táxons da macrofauna do solo no Núcleo Gurupi (A), Núcleo Livramento (B), Núcleo Igarapé-Açú (C), Núcleo São Luis (D) e Núcleo Tomé-Açú (E). 
